and severe outcomes. SARS is a new disease, and there are many features of SARS that might be similar to an outbreak caused by an unknown biological warfare agent, to include initial symptoms being non-specific and common, high attack rates, respiratory transmission, little or no understanding of the etiology and origin of the disease, and high public fear and anxiety. The World Health Organization, through the Global Outbreak Alert and Response Network, led the international response to SARS.

SARS has taught many lessons for detecting and responding to such an outbreak. These lessons include the importance of preparedness, global surveillance, global leadership, a scientific basis to control measures, transparency, surge capacity, international collaboration, and communications. These lessons can be applied to assess and improve global capacity to respond to other infectious disease threats most notably the next influenza pandemic and the possible deliberate use of a biological agent.

Keywords: collaboration; communication; infectious diseases; leadership; pneumonia; preparedness; response, international; severe, acute-onset, respiratory syndrome (SARS); surveillance; surge capacity; transparency

Prebosp Disast Med 2003;18(s1)s17.

\section{Role of the OPCW in Response to Chemical Accidents}

\section{Dr. Clarence Brown}

Organisation of Prohibition of Chemical Weapons (OPCW) Concept of Assistance

Inspectorate Senior Medical Officer, Organisation for the Prohibition of Chemical Weapons, Den Haag

In accordance with Article $\mathrm{X}$ of the Chemical Weapons Convention (CWC), the Organisation for the Prohibition of Chemical Weapons (OPCW) (www.opcw.org) carries out the following implementation measures of assistance.

1. The coordination and delivery to States Parties for protection against Chemical Weapons (CW) including: (a) Detection equipment; (b) Alarm systems; (c) Protection equipment; (d) Decontamination equipment; (e) Decontaminants; (f) Medical antidotes; (g) Treatments; and $(\mathrm{h})$ Advice on any of these protective measures.

2. The OPCW is able to provide States Parties with information on protective measures against $\mathrm{CW}$, providing expert advice for capacity building, establishing a voluntary fund for assistance, and the conclusion of bilateral agreements between States Parties for offers of assistance.

3. The OPCW has adopted a programme for the establishment of permanent stockpiles of protective equipment including inspection and serviceability. Associated with the use of such stockpiles is a programme of assistance in developing emergency plans, legislation, training programmes, procedures, and standards.

4. In the case of an alleged use of $\mathrm{CW}$, the requesting State Party may request the OPCW to conduct an investigation to collect facts to determine whether $\mathrm{CW}$ has been used.

This presentation will provide further insight into the role that OPCW has in the provision of assistance to States Parties under Article $\mathrm{X}$ of the CWC.
Keywords: advice; assistance; chemical weapons; Chemical Weapons Convention (CWC); equipment; funding;

Organisation for the Prohibition of Chemical Weapons

(OPCW); protection; stockpiles

Prehosp Disast Med 2003;18(s1)s17.

E-mail: clarence.brown@opcw.org

\section{Preventing the Militarization of Biology: Biological Warfare Past, Present, and Potential Future \\ Prof. Malcom Dando; ${ }^{1}$ Prof. M.L. Wheelis ${ }^{2}$ \\ 1. Dept. of Peace Studies, University of Bradford, Bradford, UK \\ 2. University of California-Davis, Sacramento, California, USA}

There is increasing concern relative to the possible use of biological weapons of mass destruction. This current concern is set in the context of the history of offensive biological weapons programs over the last 100 years. It is argued that while the present threat is limited, it could escalate substantially over the next decades. All previous scientific and technological solutions have been applied in major ways to military purposes, and this looks as if it also will happen to the ongoing revolution in the life sciences.

The potential outcomes of significant militarization of biology are detailed in two key areas: (1) microbiology and (2) neuroscience. It is argued that the potential outcomes are in nobody's interest, and that all possible means should be undertaken to prevent militarization of biology.

Keywords: microbiology; military; neurosciences; outcomes; revo-

lution of life sciences; weapons, biological; weapons of mass destruction

Prehosp Disast Med 2003:18:s(1)s17.

E-mail: mrdando@bradford.ac.uk

\section{Disaster Medicine}

\author{
Hospital Disaster and Emergency Planning \\ Jeffrey Arnold, MD, FACEP, FAAEM \\ Department of Emergency Medicine, Baystate Medical Center, \\ Tufts University School of Medicine, Springfield, Massachusetts \\ USA
}

For the past decade, at least one disaster has occurred somewhere every day, affecting hospitals throughout the world. ${ }^{1}$ With increasing population growth and maldistribution, increasing urbanization, increasing environmental degradation, and continuing economic imbalance, the impact of disasters or emergencies on hospitals is likely to increase. Hospitals play a critical role in the local response system to emergencies, providing: (1) initial triage, decontamination, and emergency medical care for victims able to flee the disaster scene; (2) definitive medical care for the vast majority of victims; and (3) continued medical care to the community with ongoing medical problems.

This presentation considers the process and structure of effective hospital emergency planning. Hospital emergency planning optimally incorporates processes that are multidisciplinary, evidence-based, relevant to the community at risk, and cost-effective. Components of the hospital disaster plan include the plan definition including risk assessment, coordination and control system, plan activation, medical operations, logistical operations, planning operations 
including emergency preparedness and information acquisition and exchange, and financial operations. The Hospital Emergency Incident Command System provides a useful framework for understanding the multiple interconnected functions of hospital emergency response that must be addressed in the hospital emergency plan.

\section{References}

1. International Federation of Red Cross and Red Crescent Societies: Disaster data: Key trends and statistics. In: Walter J (ed), World Disaster Report 2003. Geneva: International Federation of Red Cross and Red Crescent Societies, 2003, p 181.

Keywords: disaster; emergency; hospital emergency incident command system (HEICS); hospitals; plan; planning; preparedness; response;

Prehosp Disast Med 2003;18(s1)s17.

\section{Integrating Army and Civilian Weapons of Mass Destruction Incident Response \\ Tom Stein, $M D$ \\ United States Army}

The concept of U.S. Army Special Medical Augmentation Response Teams (SMART) will be introduced. How the military expertise on weapons of mass destruction (WMD) can be integrated into the civilian response system as well as the civilian incident command system.

Keywords: civilian; integration; military; U.S. Army Special

Medical Augmentation Response Teams (SMART); weapons of mass destruction (WMD)

Prehosp Disast Med 2003:18:s(1)s18

E-mail: tstein@wpahs.org

\section{Mass Casualty Situations: Usefulness of UN Guidance on the Use of Military Civil Defence Assets in Disasters and Complex Emergencies \\ Col. Silvio Porcu, IT AF \\ Medical Staff Officer, IMS-NATO HQs, Brussels Belgium}

A "Mass Casualty Situation is one in which an excessive disparity exists between the casualty load and the medical capabilities locally available for its conventional management." Many natural, technological, and environmental disasters involve mass casualties and create peaks of overload on the health and emergency medical services.

International Disaster Relief Assistance (IDRA) means material, personnel, and services provided by the international community to a Receiving State to meet the needs of those affected by a disaster. In 1994, the United Nations Department of Humanitarian Affairs (UN DHA) formalised the Guidelines On the Use of Military and Civil Defence Assets (MCDA) in Disaster Relief. According to these non-binding guidelines (the so called "Oslo Guidelines"), foreign military and civil defence organisations can provide personnel, equipment, supplies, and services for IDRA.

This year, UN Office for the Co-ordination of Humanitarian Affairs (OCHA) launched the new Guidelines on the Use of MCDA in Complex Emergencies that complement the "Oslo Guidelines". The author underlines the main differences between the UN-established principles, tasks and responsibilities of the UN-led peacetime humanitarian assistance operations, and the meaning and the value of the civil-military co-operation (CIMIC) and humanitarian assistance in the broad spectrum of possible operations carried out under military and NATO leadership: Euro-Atlantic Disaster Response Co-ordination Center (EADRCC), combat missions, peace-enforcing, and peace keeping. Furthermore, the author underlines the need of a more accurate reference, in the UN Guidelines, to the medical issues of mass casualty situations and to the requirements for Consequence Management following the use of weapons of mass destruction against civilian population: the military may be the only organisation with good capabilities to operate in an NBCR environment!

Keywords: civilian; consequence management; cooperation; disasters; emergency medical services; guidance; health services; international disaster relief assistance; mass casualties; military;

NATO; weapons of mass destruction

Email: lar.med@hq.nato

Prehosp Disast Med 2003;18:s(1)s18.

\section{Disaster Medicine: Lessons Learned}

\section{Deployment of a Field Hospital into Disaster Areas \\ LTC (Ret.) Mauricio Lynn, MD}

Ryder Trauma Center, Jackson Memorial Hospital, University of Miami School of Medicine, Miami, Florida, USA

The deployment of a field hospital into a disaster area is a major logistical and economical enterprise. A field hospital usually is required for sudden-onset, natural disasters such as earthquakes where local healthcare facilities are partially or completely destroyed or for a humanitarian crisis, when no other medical care is available. Access routes to and from the field hospital, including a nearby landing zone are of extreme importance when choosing its location.

The epidemiological distribution of the majority of patients who seek care at a field hospital basically is the same as the distribution seen at a standard, hospital emergency room: Medical and non-traumatic surgical emergencies. A surge in the number of patients with respiratory problems, an acute myocardial event, and premature deliveries should be expected due to sudden and intense stress. Since the time elapsed from the disaster to the actual activation of the field hospital may require several hours or more, the majority of patients with "disaster-related injuries" will present with fractures, minor burns, contusions, and lacerations.

Personnel qualifications and specific equipment and supplies should be organized according to the expected epidemiological distribution of patients. Vaccinations, sewage treatment, water, and fresh food supply are a few of the logistical issues to be considered to ensure the health of the deployed personnel.

Keywords: deployment; equipment; field hospitals; logistics; personnel; qualifications; siting; supplies

Prehosp Disast Med 2003;18(s1)s18.

Email: MLynn@med.miami 